\title{
A sperm-specific enolase
}

\author{
Yvonne H. Edwards and J. A. Grootegoed* \\ M.R.C. Human Biochemical Genetics Unit, Galton Laboratory, University College London, \\ Wolfson House, 4 Stephenson Way, London NW1 2HE, U.K. and \\ *Department of Biochemistry, Medical Faculty, Erasmus University, Rotterdam, The Netherlands
}

\begin{abstract}
Summary. An unusual enolase isoenzyme, ENOS, was found in human, ram and mouse spermatozoa. This isoenzyme is unique to spermatozoa and distinguished from the somatic enolases ENO 1, ENO 2 and ENO 3 by electrophoretic mobility, high thermostability and ability to undergo structural alteration at high temperatures. The pattern of expression of ENO $S$ during sperm differentiation suggests that this isoenzyme is synthesized relatively late in the presence of a haploid genome.
\end{abstract}

\section{Introduction}

In developing male germ cells several gene loci encode proteins synthesized at no other time and in no other place; examples include lactate dehydrogenase X (LDH X, Goldberg, 1976), phosphoglycerate kinase 2 (PGK2, Van der Berg, Cooper \& Close, 1973), cytochrome ct (Hennig, 1975), and testis-specific basic nuclear protein (Goldberg, Geremia \& Bruce, 1977). This paper reports the existence of an unusual form of enolase (2-phospho-D-glycerate hydrolase, EC 4.2.1.11) designated ENO $\mathrm{S}$ which is distinct from the enolases of somatic tissues and is restricted to the later stages of sperm maturation.

We have previously shown that human enolases are dimeric and are determined by three gene loci $E N O 1, E N O 2$ and ENO 3 which encode the polypeptides $\alpha, \beta$ and $\gamma$ respectively (Pearce, Edwards \& Harris, 1976). The $\alpha \alpha$ homodimer has a very broad tissue distribution and is the major isoenzyme in most tissues except skeletal and cardiac muscle where the $\gamma \gamma$ isoenzyme predominates. The product of ENO2 is most prominent in brain and indeed the $\beta \beta$ isozyme has been referred to as the 'neuronal specific' enolase (NSE, Schmechel, Marangos \& Broghtman, 1979) although this gene is expressed in a wide variety of cell types as evidenced by the occurrence of the $\alpha \beta$ heterodimer. A similar multigene determination and tissue distribution for the various gene products have been reported for the rat somatic tissues (Rider \& Taylor, 1974).

\section{Materials and Methods}

Preparation of samples. Fresh human spermatozoa were obtained as ejaculates from 13 unrelated normal donors $\left(\sim 3.5 \times 10^{8}\right.$ spermatozoa $\left./ \mathrm{ml}\right)$ and from 75 men attending an infertility clinic. Of these, 66 samples contained $>10^{7}$ but $<10^{8}$ spermatozoa $/ \mathrm{ml}$ and 9 were oligospermic with $<10^{7}$ spermatozoa/ml. Electroejaculated ram spermatozoa were collected from an animal selected at random from the stock of the Zoological Society of London. The spermatozoa were pelleted by centrifugation ( $2000 \mathrm{~g}, 5 \mathrm{~min}$ ) and washed extensively in phosphate-buffered saline and lysed by sonication. 
Testicular tubules were isolated using collagenase from the testes of 2-month-old Swiss random bred mice. Suspensions of tubular cells were prepared with trypsin as previously described (Grootegoed, Kruger-Sewnarain, Jutte, Rommerts \& van der Molen, 1982). Fractions enriched in middle-late pachytene spermatocytes, round spermatids or elongating spermatids with their detached cytoplasmic fragments were obtained after cell separation by sedimentation at unit gravity (Meistrich, Bruce \& Clermont, 1973; Grootegoed, Grolle-Hey, Rommerts \& van der Molen, 1977). Spermatozoa were isolated from the vas deferens and cauda epididymidis. Isolations were carried out in Dulbecco's buffered saline supplemented with $1 \mathrm{mM}$-sodium pyruvate and $6 \mathrm{~mm}$ sodium DL-lactate. The separated cells were washed twice by centrifugation for $10 \mathrm{~min}$ at $200 \mathrm{~g}$ and kept frozen at $-80^{\circ} \mathrm{C}$.

Tissue extracts used as control isoenzyme marker specimens were prepared by homogenization of the tissue in water $(1: 1, \mathrm{w} / \mathrm{v})$ and removal of cell debris by centrifugation at $15000 \mathrm{~g}$ for $20 \mathrm{~min}$ at $4 \mathrm{C}$.

Electrophoretic analysis of enolase isoenzymes was carried out in a starch gel (11\%) in $10 \mathrm{~mm}$ EDTA, $10 \mathrm{~mm}-\mathrm{MgCl}_{2}$ and $10 \mathrm{~mm}$-maleic anhydride at $\mathrm{pH} 7 \cdot 4$ exactly as described previously (Pearce et al., 1976): $5 \mathrm{~V} / \mathrm{cm}$ were applied for $6 \mathrm{~h}$ at $4^{\circ} \mathrm{C}$. The electrode buffer was 10 times the concentration of the gel buffer (Pearce et al., 1976). Electrophoretic analysis of lactate dehydrogenase isoenzymes $(\mathrm{LDH})$ was carried out in an $11 \%$ starch gel in $10 \mathrm{~mm}$-phosphate $\mathrm{pH} 7 \cdot 0$ at $4^{\circ} \mathrm{C}$ and $4 \mathrm{~V} / \mathrm{cm}$ for $17 \mathrm{~h}$. The electrode buffer was 10 times the concentration of the gel buffer (Harris \& Hopkinson, 1976). Phosphoglycerate kinase (PGK) isoenzymes were visualized after electrophoresis on cellogel in $20 \mathrm{~mm}$-diethyl barbituric acid, $10 \mathrm{~mm}$-sodium citrate, $5 \mathrm{~mm}-\mathrm{MgSO}_{4}, 2$ mM-EDTA, $10 \mathrm{~mm}$-dithiothreitol. The cellogel was electrophoresed for $1.5 \mathrm{~h}$ at $20^{\circ} \mathrm{C}$ and $200 \mathrm{~V}$ (Bücher, Bender, Fundele, Hafner \& Linke, 1980).

After electrophoresis isoenzymes were visualized using specific enzyme stains made up in 50 mM-Tris/Cl buffer pH 7.6 (LDH, ENO) and 0.1 M-triethanolamine, $20 \mathrm{~mm}-\mathrm{MgSO}_{4}$ (PGK) applied in a filter paper or agar overlay. The stain solution for enolase contained $4 \mathrm{mM}-3$-phosphoglycerate, $1 \mathrm{~mm}-\mathrm{NADH}, 2 \mathrm{~mm}-\mathrm{ADP}, 4 \mathrm{~mm}-\mathrm{MgCl}_{2}, 2.5$ units phosphoglyceromutase $/ \mathrm{ml}, 2.75$ units lactate dehydrogenase $/ \mathrm{ml}$ and 4.0 units pyruvate $\mathrm{kinase} / \mathrm{ml}$ (Pearce et al., 1976). The stain solution for LDH contained $8 \mathrm{~mm}$-calcium lactate, $1 \mathrm{~mm}-\mathrm{NAD}$, and methyl thiazolyl blue and phenazine

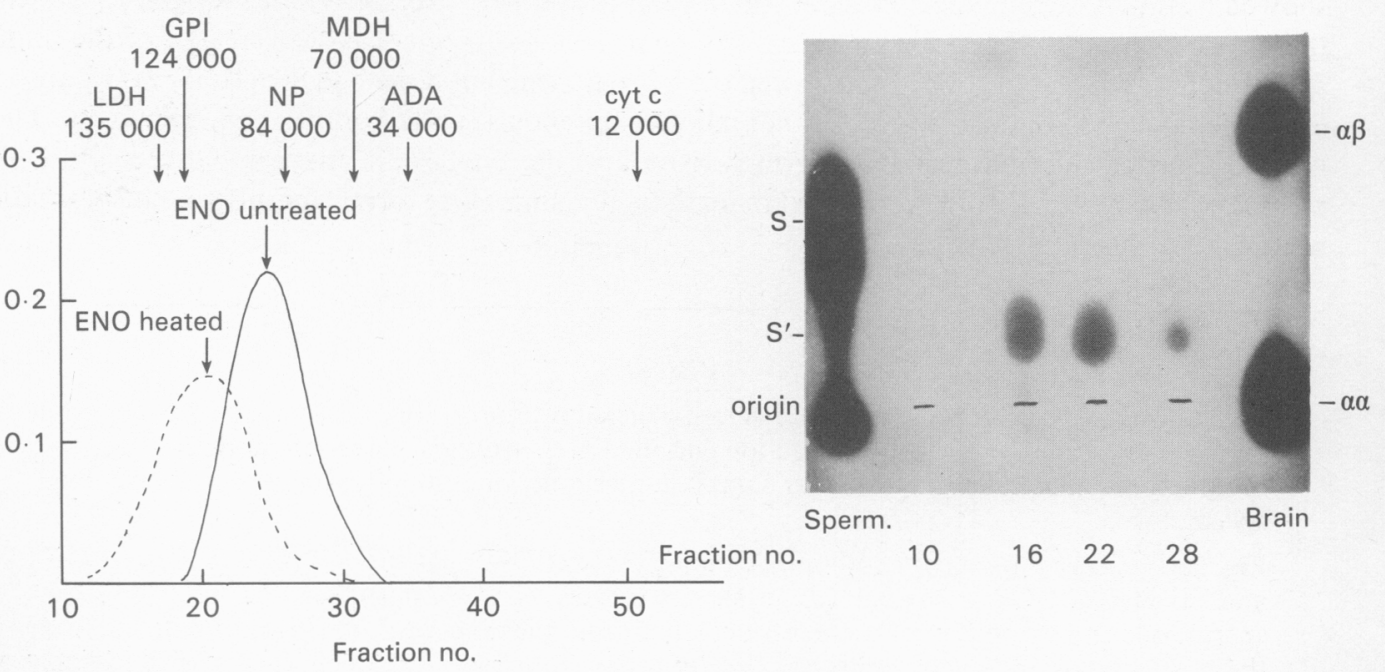

Text-fig. 1. The elution of human sperm enolase activity from Sephadex G200. In one case a fresh sample whose activity was largely attributable to the $\mathrm{S}$ isoenzyme was applied to a column equilibrated and eluted at $6^{\circ} \mathrm{C} \mathrm{(-)} \mathrm{and} \mathrm{in} \mathrm{the} \mathrm{other} \mathrm{the} \mathrm{sample} \mathrm{was} \mathrm{heated} \mathrm{to} 55^{\circ} \mathrm{C}$ for $40 \mathrm{~min}$

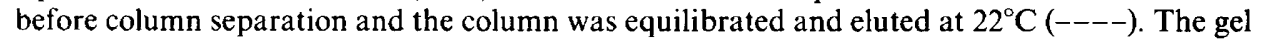
photograph shows the enolase isoenzymes in fractions produced from the latter experiment. 


\section{PLATE 1}

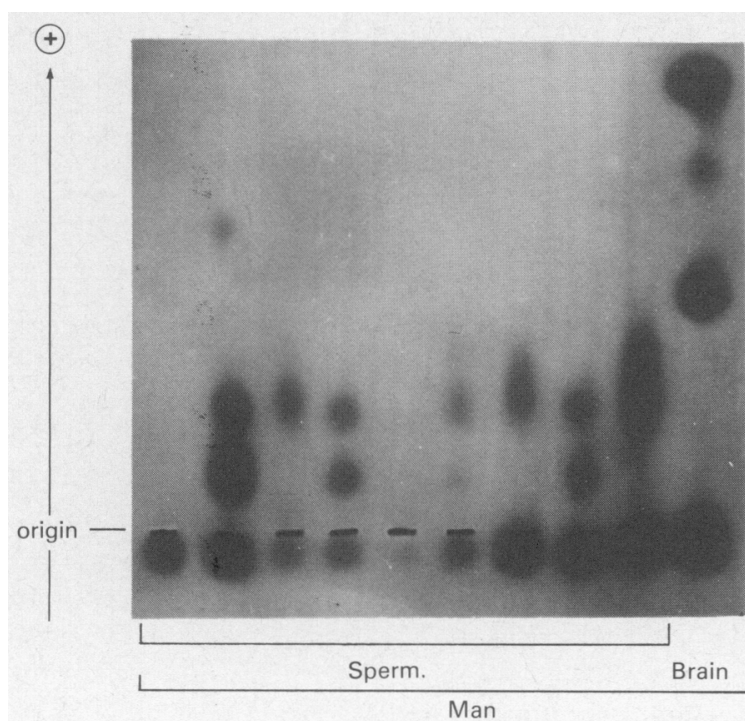

Fig. 1

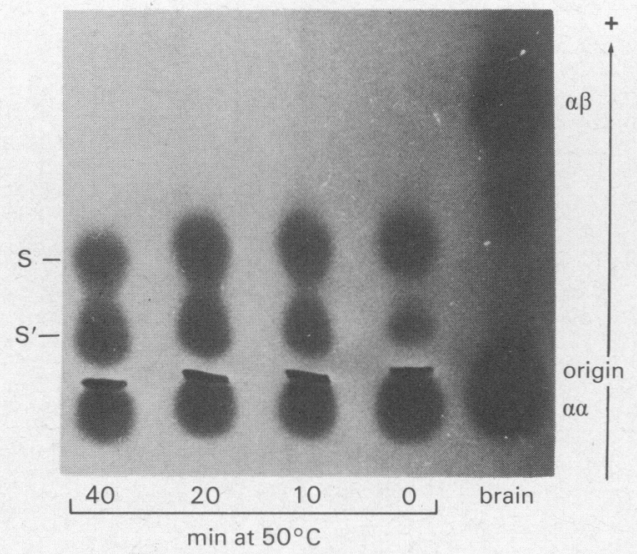

Fig. 3

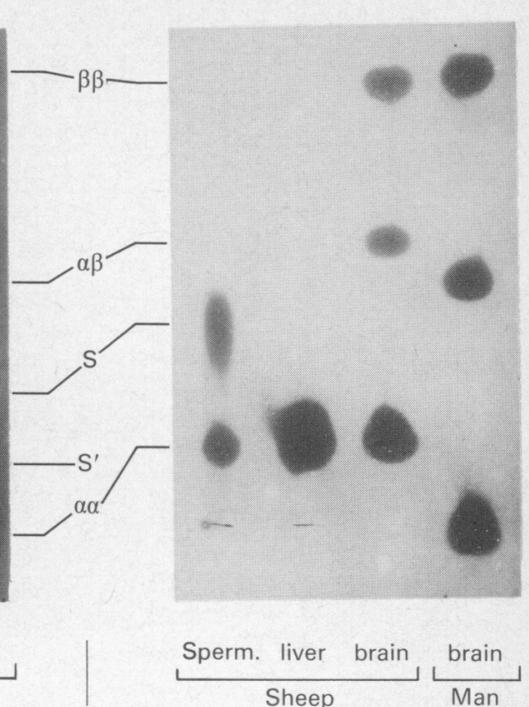

Fig. 2

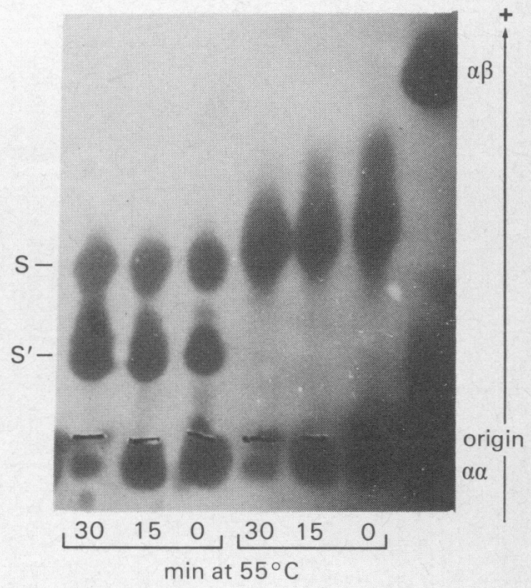

Fig. 1. Enolase isoenzymes seen in human sperm lysates from different unrelated individuals and in a human brain specimen. The unlabelled enolase isoenzyme between $\alpha \beta$ and $\beta \beta$ in the human brain specimen is a secondary isoenzyme derived from $\beta \beta$ (described by Pearce et al., 1976).

Fig. 2. Enolase isoenzymes seen in spermatozoa, liver and brain of a sheep. A human brain sample is included for comparison.

Fig. 3. Heat stability of human sperm enolase isoenzymes. Freshly prepared lysates from 3 different unrelated individuals were heated in a water bath at 50 or $55^{\circ} \mathrm{C}$ and aliquants were removed onto ice at 10 - or 15 -min intervals before electrophoretic analysis. 
PLATE 2

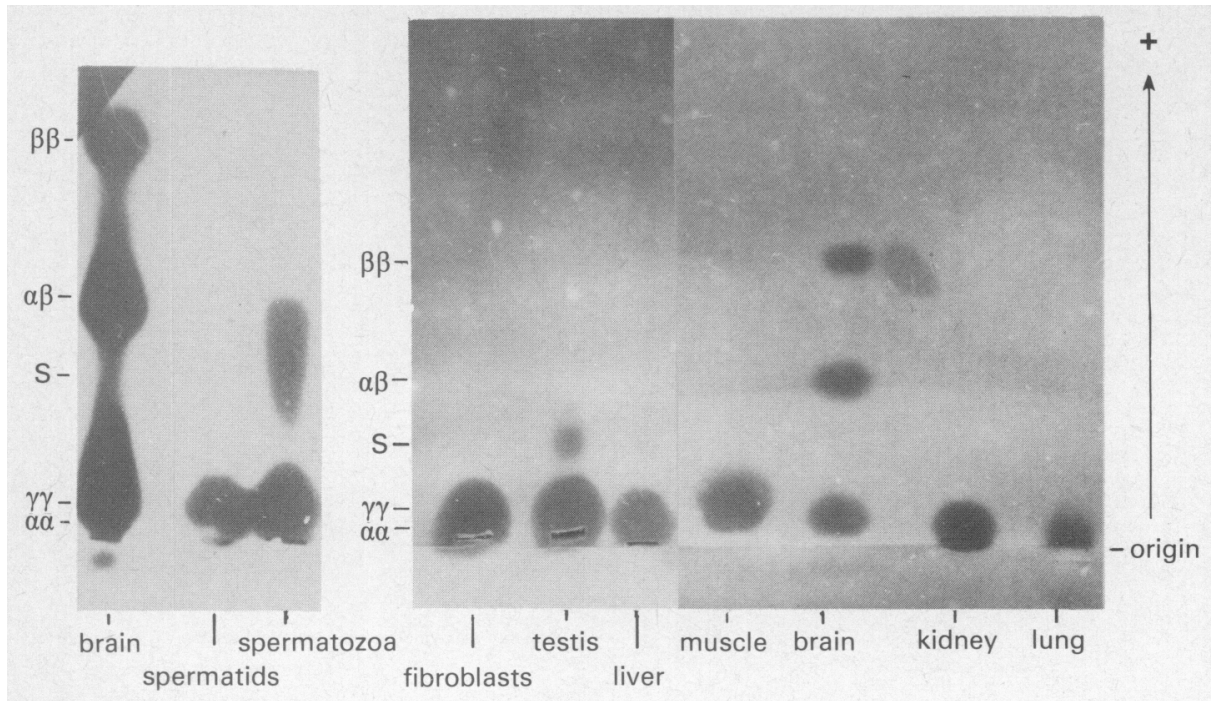

Fig. 4
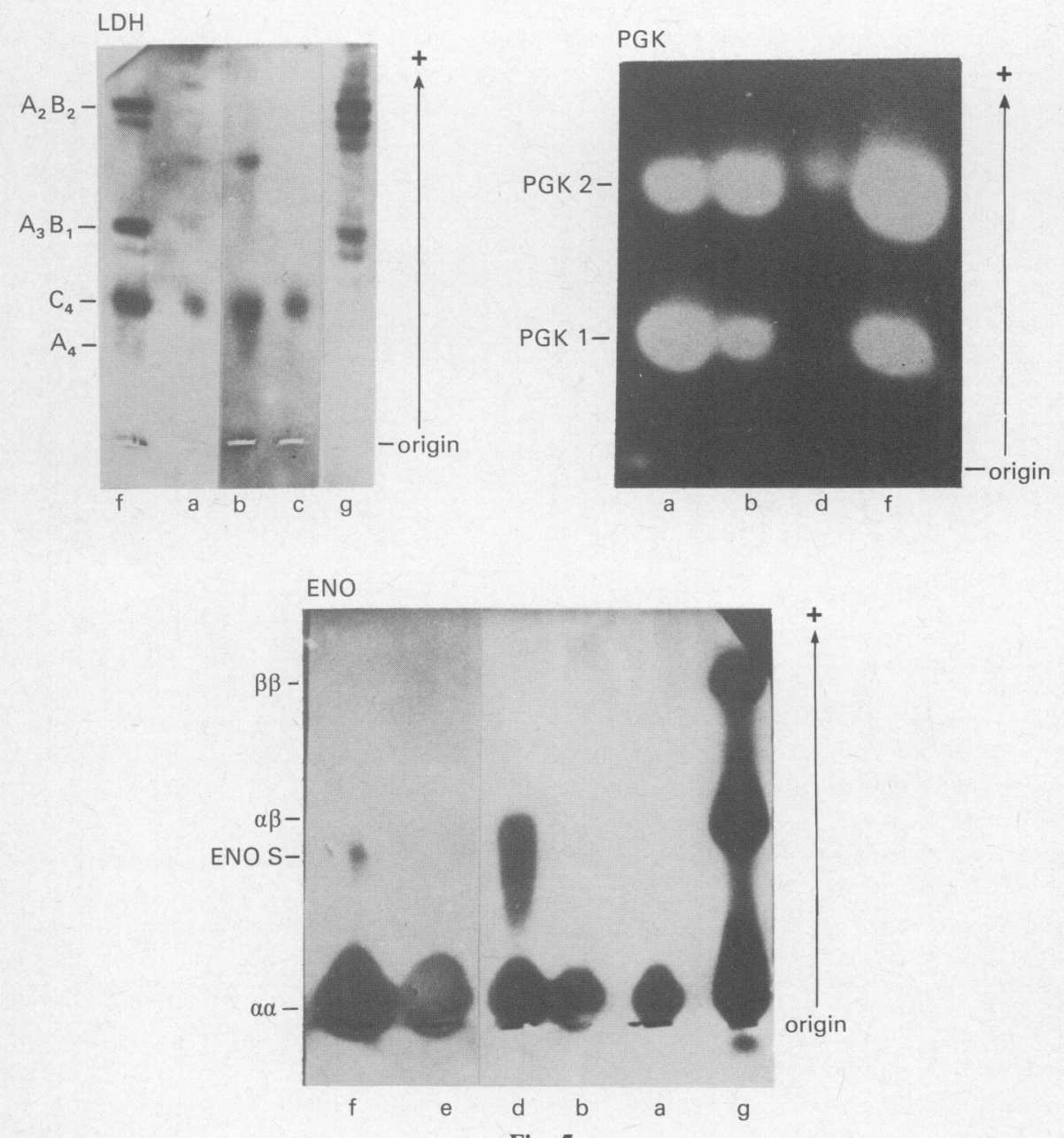

Fig. 5 
methosulphate at $5.0 \mathrm{mg}$ and $2.5 \mathrm{mg}$ per $20 \mathrm{ml}$ stain respectively (Harris \& Hopkinson, 1976). The stain solution for PGK contained 15 mm-potassium phosphate pH 7.6, 0.4 mм-NAD, 12 mмfructose diphosphate, $15 \mathrm{~mm}$-glucose, $2.5 \mathrm{~mm}-\mathrm{ADP}, 4 \cdot 0 \mathrm{~mm}-\mathrm{NADP}, 13 \mathrm{~mm}-\mathrm{MgSO}_{4} 0.3$ units aldolase, 1 unit glucose 6 phosphate dehydrogenase, 1 unit glycerol phosphate dehydrogenase, 3 units glyceraldehyde 3 phosphate dehydrogenase and 6.5 units hexokinase.

Enolase isoenzymes were visualized as dark zones on a fluorescent background under ultraviolet light. LDH isoenzymes appeared as zones of dark blue formazan in daylight and PGK isoenzymes as fluorescent spots on a dark background under ultraviolet light.

Enolase assay. Enolase activity was assayed spectrophotometrically at $340 \mathrm{~nm}$ by coupling the reaction with pyruvate kinase and lactate dehydrogenase to give oxidation of $\mathrm{NADH}$. The reaction was carried out at $30^{\circ} \mathrm{C}$ in a final volume of $1.0 \mathrm{ml}$ containing $80 \mathrm{~mm}-\mathrm{KCl}, 8 \mathrm{~mm}-\mathrm{MgCl}, 2 \mathrm{~mm}-$ EDTA, 2 mM-ADP, 1 mM-NADH, 50 mm-triethanolamine buffer $\mathrm{pH} 7.5,1.5$ units pyruvate kinase, and 3.6 units lactate dehydrogenase. The assay was started by the addition of substrate, 1 mM-2-phosphoglycerate.

Molecular size determinations. Washed human sperm samples (4-6) were pooled to provide adequate material for chromatography. Gel filtration chromatography was carried out using Sephadex G200 in a column $2.5 \times 50 \mathrm{~cm}$ with a flow rate of $12 \mathrm{ml} /$ hour. The equilibration and elution buffer was $50 \mathrm{~mm}$-Tris/ $\mathrm{Cl}, 100 \mathrm{mM}-\mathrm{NaCl} \mathrm{pH} 7.5$ and fractions of $2.5 \mathrm{ml}$ were collected. The proteins used to calibrate the column were lactate dehydrogenase $\left(M_{r} 40000\right)$, glucose phosphate isomerase $\left(M_{r} 124000\right)$, nucleoside phosphorylase $\left(M_{r} 83000\right)$, malate dehydrogenase $\left(M_{r} 70000\right)$, adenosine deaminase $\left(M_{r} 34000\right)$ and cytochrome $c\left(M_{r} 12000\right)$.

\section{Results}

\section{Human spermatozoa}

At least 2 and sometimes 3 enolase isoenzymes were seen in sperm lysates (Pl. 1, Fig. 1), the least anodal isoenzyme was identified as the $\alpha \alpha$ homodimer coded by ENO 1 . The more anodal isoenzymes $\mathrm{S}$ and $\mathrm{S}^{\prime}$ did not correspond in electrophoretic mobility to other enolase isoenzymes but showed a similar dependence on 2-phosphoglycerate and $\mathrm{Mg}^{2+}$ for activity as judged by omitting these reagents in turn from the gel stain. The enolase $\mathrm{S}$ isoenzyme was seen in $90 \%$ of the human sperm samples and about $30 \%$ also showed the $S^{\prime}$ isoenzyme but none had $S^{\prime}$ activity in the absence of S. The other $10 \%$ of samples were either inactive for enolase or had only the $\alpha \alpha$ isoenzyme. There was no clear correlation between sperm density and the enolase isoenzyme pattern although 2 samples not exhibiting $\mathrm{S}$ or $\mathrm{S}^{\prime}$ contained more than $30 \%$ immature forms, mainly round spermatids, according to hospital records.

\section{PLATE 2}

Fig. 4. Enolase isoenzymes seen after starch gel electrophoresis of extracts from various adult mouse tissues, spermatozoa and a fraction enriched in spermatids. The $S$ component is seen as a relatively weak zone in the testicular sample but as a major component in washed, ejaculated spermatozoa.

Fig. 5. Isoenzyme patterns of lactate dehydrogenase (LDH), phosphoglycerate kinase (PGK) and enolase (ENO) in (a) pachytene spermatocytes, (b) round spermatids, (c) elongating spermatids and cytoplasmic fragments detached from these spermatids, (d) spermatozoa from the vas deferens and cauda epididymidis, (e) testes from 7-day-old mice, (f) testis from adult mice, and $(\mathrm{g})$ brain. The separated cells were kept frozen at $-80^{\circ} \mathrm{C}$ and extracted in water. Specific stains to reveal the LDH, PGK and ENO isoenzymes are given by Harris \& Hopkinson (1976). The isoenzymes anodal to $\mathrm{LDH} \mathrm{C}_{4}$ in fractions (a) and (b) have the electrophoretic mobilities expected for the heterotetramers $C_{3} B_{1}$ and $C_{2} B_{2}$. Such isoenzymes have been detected in bull sperm samples (Georgiev, 1982). 
Several adult post-mortem specimens of human testes were examined and found to show in every case a prominent $\alpha \alpha$ enolase isoenzyme, as expected, and an ENO S component.

The thermostabilities of ENO S and the other enolase isoenzymes were compared. In one set of experiments samples were electrophoresed without prior heat treatment, the gel was sliced into identical halves, one of which was kept cold while the other was heated at $55^{\circ} \mathrm{C}$ for $20 \mathrm{~min}$. The relative activities of the isoenzymes displayed by specific activity staining were then compared. The $\alpha \alpha$ isoenzyme lost almost all activity, $\alpha \beta$ was reduced, $\beta \beta$ activity remained the same but the activities of $S$ and $S^{\prime}$ were markedly elevated. In other experiments lysates and extracts were heated in a water bath at different temperatures for various times before analysis. The $\alpha \alpha$ isoenzyme was least stable and lost more than $70 \%$ of activity after $30 \mathrm{~min}$ at $55^{\circ} \mathrm{C}$ while the $\alpha \beta$ isoenzyme was reduced by $50 \%$. In contrast the sperm-specific enolases showed activation at these elevated temperatures. In most cases ( 7 out of 8 tested) this appeared to be associated with an increase in the relative activity of the ENO S' isoenzyme and this effect is illustrated in P1. 1, Fig. 3. In one unusual case activation occurred but was not associated with the occurrence of the $\mathrm{S}^{\prime}$ isoenzyme (Pl. 1, Fig. 3).

Molecular size comparisons by gel filtration chromatography indicated that ENO $\mathrm{S}\left(\mathrm{M}_{\mathrm{r}}\right.$ $90000 \pm 3600)$ was similar to the somatic tissue enolases $\left(M_{r} 89000\right.$; Rider \& Taylor, 1974; Pearce et al., 1976). The enolase $S^{\prime}$ appeared to be larger $\left(M_{r} 124000 \pm 7000\right.$; Text-fig. 1). This determination was carried out using a sperm lysate heated at $55^{\circ} \mathrm{C}$ for 40 min before chromatography in order to boost the level of $S^{\prime}$ activity. Under these conditions only $S^{\prime}$ was recovered in the eluate.

\section{Ram spermatozoa}

Spermatozoa from 1 ram showed an isoenzyme with an electrophoretic mobility between the $\alpha \alpha$ and $\alpha \beta$ isoenzymes characteristic of sheep brain. This isoenzyme is not found in somatic tissues and is presumably homologous with the human ENO S isoenzyme. There was no evidence for ENO S' in this single sample and heat activation studies were not carried out (Pl. 1, Fig. 2).

\section{Mouse spermatozoa}

A sperm-specific enolase isoenzyme was demonstrated in extracts of mouse spermatozoa and mature testes. This component had an electrophoretic mobility between ENO $\alpha \alpha$ and $\alpha \beta$ isoenzymes characteristic of mouse brain, was relatively intense in spermatozoa, could be seen as a weak component in whole testis homogenates but was not found in any other mouse tissue including cultured cells (PI. 2, Fig. 4). A component equivalent to human ENO S' was not identified but the number of individual mice scrutinized was small $(N=5)$. Heat activation studies were not carried out. The main objective in the analyses of the mouse enolase was to examine the expression of activity at different stages of spermatogenesis.

Four fractions were available: (a) in which the major cell type $(78 \%)$ was middle and late pachytene spermatocytes; fraction (b) was mainly $(82 \%)$ round spermatids; (c) contained largely elongating spermatids and their detached cytoplasmic droplets $(94 \%)$ and (d) washed spermatozoa. The ENO S isoenzyme was present only in fractions (c) and (d), although in each of the 4 fractions there was enolase activity attributable to $\alpha \alpha$ (Pl. 2, Fig. 5, ENO). Evidence for LDH X and PGK 2 isoenzymes was found in all 4 fractions (Pl. 2, Fig. 5, LDH, PGK).

\section{Discussion}

The data presented in this paper indicate that the enolase, ENO S, found in the spermatozoa of different mammalian species is unique to that tissue. In common with the somatic tissue enolases, 
the ENO $\mathrm{S}$ isoenzyme has a molecular weight of around 90000 and is dependent on 2phosphoglycerate and $\mathrm{Mg}^{2+}$ for activity. However, the ENO $\mathrm{S}$ and $\mathrm{S}^{\prime}$ isoenzymes are distinguished from the somatic tissue enolases by relatively high thermostability and in particular $\mathbf{S}^{\prime}$ appears to increase in activity at elevated temperatures. The nature of the $S^{\prime}$ isoenzyme is still obscure: it could be a modified form of the $\alpha \alpha$ isoenzyme, represent an $\alpha / \mathrm{S}$ hybrid enolase molecule generated by dissociation and recombination at raised temperature, or generated from enolase $S$. The first suggestion seems unlikely since the thermal inactivation profile of $\alpha \alpha$ in liver preparations, which contain only this isoenzyme, is the same as in sperm lysates but is not associated with the appearance of novel isoenzymes. The possibility that $S^{\prime}$ is an $\alpha / S$ heterodimer has been investigated by attempting to generate the $S^{\prime}$ isoenzyme in vitro by subjecting mixtures of the $\alpha \alpha$ and $S$ isoenzymes to dissociation-rehybridization procedures. Mixtures of isoenzymes were either heated at $55^{\circ} \mathrm{C}$ for various times or were subjected to repeated freezing and thawing in the presence of high salt $(2 \mathrm{M}-\mathrm{NaCl})$, before electrophoresis. The latter procedure has proved successful in the formation of $\alpha \beta$ and $\gamma \beta$ heterodimers in vitro from mixtures of $\alpha \alpha, \beta \beta$ and $\gamma \gamma$ isoenzymes (Pearce et al., 1976), but numerous attempts using various modifications of the basic procedures did not lead to the appearance of new isoenzymes in the $\alpha \alpha, S$ mixture. The appearance of $S^{\prime}$ only when the $S$ isoenzyme occurs makes the possibility that $S^{\prime}$ is generated from the $S$ isoenzyme the most attractive of the three explanations. If this were the case then the differences in the apparent molecular size of the $S$ and $S^{\prime}$ isoenzymes suggest that ENO S' may be generated from ENOS either by aggregation of the ENO S molecules with each other or with some other protein in the sperm lysate, or that $S^{\prime}$ is a conformer of $S$ with a larger effective radius and improved stability.

At this stage it is not possible to comment on the functional significance of this sperm-specific enolase isoenzyme but it is relevant to note that enolase catalyses a reaction in the EmbdenMeyerhoff glycolytic pathway in which two other enzymes, lactate dehydrogenase and phosphoglycerate kinase, are each characterized by a sperm-specific isoenzyme (LDH X and PGK 2) which is coded by a locus independent of those expressed in somatic tissues. Autosomally-coded PGK 2 seems to replace X-chromosomally coded PGK 1 which gradually disappears after formation of the heterochromatic XY body at the early pachytene stage. LDH X may be involved in lactate metabolism by spermatocytes, spermatids and spermatozoa, and may take part in unique shuttle systems for oxidation of cytosolic NADH (Storey \& Kayne, 1977; Gerez de Burgos, Burgos, Montamat, Morens \& Blanco, 1978; Jutte, Grootegoed, Rommerts \& van der Molen, 1981). The unusually high thermostability of enolase ENO S may indicate that this isoenzyme contributes to the highly specialized performance of mature spermatozoa.

The pattern of expression of ENOS is rather different from that of LDH X and PGK 2. ENOS has been demonstrated only in fractions enriched in elongated spermatids and spermatozoa, suggesting that synthesis occurs several days after reduction division when the developing germ cells are haploid. We have found that LDH X and PGK 2 are demonstrable at relatively early stages of spermiogenesis, before reduction division. The finding of expression of LDH X in fractions enriched in pachytene spermatocytes is in agreement with earlier reports (Blackshaw \& Elkington, 1970; Goldberg \& Hawtrey, 1976), but the demonstration of PGK 2 at this early stage is in contrast to the conclusion based on immunofluorescence analysis (Van der Berg, Lee \& Goldberg, 1981; Kramer, 1981) that mouse PGK 2 is not demonstrable until the late spermatid stage.

Although the relatively late synthesis of ENOS in spermiogenesis contrasts with that found for LDH X and PGK 2 there are other sperm-specific proteins which show a rather late appearance during spermatogenesis. For example, the sperm autoantigens $\mathrm{S}, \mathrm{P}$ and $\mathrm{T}$ are found in haploid germinal cells but are totally absent from the diploid spermatogonia and primary spermatocytes (Radu \& Voisin, 1975), and the testis-specific basic nuclear protein does not appear until the spermatid stage of differentiation (Goldberg et al., 1977).

If enolase $S$ is the product of a gene locus distinct from those determining the somatic-tissue enolases, the ENO-S locus is either expressed in the haploid genome or a stable mRNA is transcribed premeiotically and stored untranslated until the late spermatid stage of development. 
There are observations to support the view that both types of mechanism may operate during sperm differentiation. For example, Geremia, D'Agostino \& Monesi (1978) have shown that round spermatids synthesize both ribosomal RNA and poly $A^{+}$RNA and Erickson et al. (1980) have found that the synthesis of poly $\mathrm{A}^{+}$RNA did not decrease in early postmeiosis as compared to late premeiosis. Another suggestion is that the heterogeneous nuclear RNA synthesized in primary spermatocytes includes precursors for very stable mRNA (Erickson, Erickson, Betlach \& Meistrich, 1980), although Grootegoed et al. (1977) suggest that only a small portion belongs to the stable mRNA class as most of the heterogeneous RNA from spermatocytes has a short half life. Studies on protamine in trout testis (Gedamu, Dixon \& Davies, 1977) may have a bearing on the sperm-specific enolase findings. This work has shown that the protamine mRNA sequences are present in the cell in the form of mRNP particles at the prophase of meiosis. However, the translation product, protamine, does not appear until considerably later at the spermatid stage.

\section{References}

Blackshaw, A.W. \& Elkington, J.S.H. (1970) Developmental changes in lactate dehydrogenase isoenzymes in the testis of the immature rat. J. Reprod. Fert. 22, 69-75.

Bücher, T., Bender, W., Fundele, R., Hafner, H. \& Linke, I. (1980) Quantitative evaluation of electrophoretic allo- and isozyme patterns. FEBS Lett. 115, 319-324.

Erickson, R.P., Erickson, J.M., Betlach, C.J. \& Meistrich, M.L. (1980) Further evidence for haploid gene expression during spermatogenesis: heterogeneous, poly(A)-containing RNA is synthesised post-meiotically. J. exp. Zool. 214, 13-19.

Gedamu, L., Dixon, G.H. \& Davies, P.L. (1977) Identification and isolation of protamine messenger ribonucleoprotein particles from rainbow trout testis. Biochemistry, N.Y. 16, 1383-1389.

Georgiev, G.H. (1982) Study on bull sperm lactate dehydrogenase. Cell. molec. Biol. 28, 271-274.

Geremia, R., D'Agostino, A. \& Monesi, V. (1978) Biochemical evidence of haploid gene activity in spermatogenesis of the mouse. Expl Cell Res. 111, 2330.

Gerez de Burgos, N.M., Burgos, C., Montamat, E.E., Morens, J. \& Blanco, A. (1978) A shuttle system for the transfer of reducing equivalents in mouse sperm mitochondria. Biochem. Biophys. Res. Commun. 81, 644-649.

Goldberg, E. (1976) Isozymes in testes and spermatozoa. In Isozymes, Vol. 1, pp. 80-116. Eds M. C. Rattazzi, J. G. Scandalios \& G. S. Whitt. Alan R. Liss, New York.

Goldberg, E. \& Hawtrey, C. (1976) The ontogeny of sperm specific lactate dehydrogenase in mice. J. exp. Zool. 164, 309-316.

Goldberg, R.B., Geremia, R. \& Bruce, W.R. (1977) Histone synthesis and replacement during spermatogenesis in the mouse. Differentiation 7, 167-180.

Grootegoed, J.A., Grollé-Hey, A.H., Rommerts, F.F.G. \& van der Molen, H.J. (1977) Ribonucleic acid synthesis in vitro in primary spermatocytes isolated from rat testis. Biochem. J. 168, 23-31.

Grootegoed, J.A., Kruger-Sewnarain, B.C., Jutte, N.H.P.M., Rommerts, F.F.G. \& van der Molen, H.J. (1982) Fucosylation of glycoproteins in rat spermatocytes and spermatids. Gamete Res. 5, 303-315.
Harris, H. \& Hopkinson, D.A. (1976) Handbook of Enzyme Electrophoresis in Human Genetics. NorthHolland, Amsterdam.

Hennig, B. (1975) Change of cytochrome $c$ structure during development of the mouse. Eur. J. Biochem. 55, 167-183.

Jutte, N.H.P.M., Grootegoed, J.A., Rommerts, F.F.G. \& van der Molen, H.J. (1981) Exogenous lactate is essential for metabolic activities in isolated rat spermatocytes and spermatids. J. Reprod. Fert. 62, 399-405.

Kramer, J.M. (1981) Immunofluorescent localization of PGM-1 and PGM-2 isozymes within specific cells of the mouse testis. Devl Biol. 87, 30-36.

Meistrich, M.L., Bruce, W.R. \& Clermont, Y. (1973) A cellular composition of fractions of mouse testis following velocity sedimentation. Expl Cell Res. 79, 213-227.

Pearce, J.M., Edwards, Y.H. \& Harris, H. (1976) Human enolase isozymes: electrophoretic and biochemical evidence for three loci. Annls hum. Genet. Lond. 39, 263-276.

Radu, I. \& Voisin, G.A. (1975) Ontogenesis and spermatozoa autoantigen in guinea pigs. Differentiation 3, 107-114.

Rider, C.C. \& Taylor, C.B. (1974) Enolase isoenzymes in rat tissues. Electrophoretic, chromatographic, immunological and kinetic properties. Biochim. Biophys. Acto 365, 285-300.

Schmechel, D.E., Marangos, P.J. \& Broghtman, M.W. (1979) Neurone-specific enolase is a molecular marker for peripheral and central neuro-endocrine cells. Nature, Lond. 276, 834-836.

Storey, B.T. \& Kayne, F.J. (1977) Energy metabolism of spermatozoa. VI. Direct intramitochondrial lactate oxidation by rabbit sperm mitochondria. Biol. $R e-$ prod. 16, 549-556.

Van der Berg, J.L., Cooper, D.W. \& Close, P.J. (1973) Mammalian testis phosphoglycerate kinase. Nature, New Biol. 243, 48-50.

Van der Berg, J.L., Lee, C.-Y. \& Goldberg, E. (1981) Immunohistochemical localization of phosphoglycerate kinase isozymes in mouse testes. J. exp. Zool. 217, 435-441. 